\title{
BIENESTAR E INEQUIDAD: DOS CARAS DEL COOPERATIVISMO DE TRABAJO ASOCIADO*
}

Alina Marcela Bustamante Salazar

\begin{abstract}
Resumen
Las cooperativas de trabajo asociado son una forma de organización que se caracteriza por la propiedad colectiva de los medios de producción por parte de los asociados, la participación democrática de éstos en las instancias de decisión y el trabajo autogestionario; han sido consideradas como una alternativa para la generación de empleo y la inclusión a la vida laboral de grupos sociales marginados. No obstante, en los últimos años, se les acusa de servir de instrumento para flexibilizar y precarizar el trabajo. Desde estas perspectivas el artículo presenta el bienestar y la inequidad como dos caras del cooperativismo de trabajo asociado, a partir de evidencias encontradas en la revisión de literatura y en fuentes primarias.
\end{abstract}

\section{Palabras clave}

Bienestar, cooperativismo, cooperativas de trabajo asociado, inequidad.

\begin{abstract}
Worker's cooperatives are organizations which theirs partners have collective ownership of the production's means. They have democratic decisions and self-administration. Worker's cooperatives are very important because they create employment for poor people. However, they have been in recent years accused of the flexibility of the work. This paper explains why wellbeing and unfairness are two faces of the worker's cooperatives, from literature review and data collection.
\end{abstract}

\section{Key words}

Wellbeing, cooperativism, worker cooperatives, unfairness

* El artículo presenta una reflexión a partir de los hallazgos preliminares obtenidos en la fase de exploración del proyecto de investigación doctoral titulado: "Gestión humana socialmente responsable en cooperativas de trabajo asociado. Un estudio de caso en organizaciones de Antioquia y Valle”. De igual modo, es el producto del proceso investigativo realizado en el seminario Sujeto, Poder y Organización del doctorado en Administración de la Universidad EAFIT. La autora agradece las observaciones y comentarios de la doctora Silvia Ponce de HEC Montreal y los doctores Pablo Jaramillo y Francisco López de la Universidad EAFIT.

1 Estudiante de Doctorado en Administración (Universidad EAFIT), Docente de la Facultad de Ciencias Administrativas, Económicas y Contables de la Fundación Universitaria Luis Amigó. Correo E: abustam6@ eafit.edu.co 


\section{Introducción}

Las cooperativas son asociaciones sin ánimo de lucro, constituidas por personas que voluntariamente se unen, bajo principios de libre participación democrática, en igualdad de derechos y obligaciones, para satisfacer las necesidades de sus asociados y de la comunidad en general, a través de la producción de bienes y/o prestación de servicios y que respetan los principios del cooperativismo.

Si bien el modelo cooperativo está fundado sobre principios que propenden por el mejoramiento social, en Colombia, las cooperativas de trabajo asociado han sido objeto de fuertes críticas, se les acusa de perversión pues, a través de ellas, se precariza el trabajo y se violenta algunos principios constitucionales y cooperativos, como el de la libre asociación.

Así como se han denunciado los abusos cometidos por algunas cooperativas de trabajo asociado, también se pueden encontrar algunos casos en los cuales el modelo cooperativo ha tenido un impacto social y económico relevante en el mejoramiento de la calidad de vida de los asociados y de los habitantes de las regiones en las cuales se encuentra inscrito. El presente artículo, tiene como propósito explicar por qué el bienestar y la inequidad se constituyen en dos caras del cooperativismo de trabajo asociado.

La reflexión que presenta este artículo está sustentada en un estudio de enfoque cualitativo, basado en dos perspectivas: teórica y empírica. Desde el punto de vista teórico, se ha realizado una revisión de literatura -durante los años 2000 a 2010- en revistas y textos especializados en cooperativismo y gestión, ésta permite identificar los antecedentes, oportunidades de investigación y enfoques teóricos pertinentes para comprender el objeto de estudio; los resultados de esta revisión han sido publicados en otros medios, razón por la cual no se presentan aquí en detalle. Desde el punto de vista empírico, se ha recolectado información a través de entrevistas en profundidad realizadas a los asociados, directivos y personas expertas en el tema; observación no participante de los procesos de trabajo desarrollados en las cooperativas elegidas en la muestra y visitas a las viviendas de algunos asociados, de modo que la información que se presenta ha sido triangulada a través de las fuentes y técnicas de investigación empleadas. Esta información ha sido recolectada entre diciembre de 2008 y agosto de 2009.

El artículo presenta primero algunos antecedentes del cooperativismo de trabajo asociado, su relación con los mercados de trabajo, así como la normatividad colombiana que rige este tipo de organizaciones. Seguidamente, se presentan algunas evidencias que permiten calificar este tipo de organizaciones como generadoras de bienestar. Posteriormente, se describen algunas situaciones de inequidad laboral que tienen lugar en estas cooperativas. Para terminar se presentan las consideraciones finales que recogen las reflexiones del artículo. 


\section{Los avatares del mercado de trabajo: Advenimiento y crisis del cooperativismo de trabajo asociado}

El trabajo se concibe como un acto humano y un valor social cuya concepción se ha transformado con el devenir humano. En las civilizaciones antiguas, el trabajo-especialmente el "manual"- fue mal visto y se asociaba con la servidumbre, la esclavitud y el castigo ${ }^{2}$, posteriormente, con las ideas religiosas -cristianas y protestantes- y con la racionalización del mundo industrial éste fue valorizado, hasta ser considerado "un valor central en la sociedad occidental" (De Coster, 1999, p.24), puesto que a éste concierne gran parte de la actividad humana.

Desde esta perspectiva, el trabajo humano cumple con múltiples propósitos: es un medio para la realización de las personas, es una fuente de consecución de los medios de subsistencia y genera espacios para la socialización. No obstante, con el desarrollo de las sociedades industriales organizadas bajo el sistema de mercado, éste ha sido concebido principalmente bajo una visión economicista, según la cual es un factor de producción.

Según lo afirma Polanyi (1992, p.137)

"la producción es interacción entre el hombre y la naturaleza, para que este proceso se organice a través de un mecanismo autorregulador de trueque e intercambio, el hombre y la naturaleza deberán ser atraídos a su órbita, deberán quedar sujetos a la oferta y la demanda",

de modo que los factores de producción -tierra, trabajo y capital- quedan al arbitrio de las fuerzas del mercado. Así, entonces, el trabajo deja de ser un fin en sí mismo, y se constituye en un medio de producción, transable en un escenario específico: el mercado de trabajo.

Aunque no existe consenso respecto a la definición de mercado de trabajo, los autores convergen en considerar que éste

"tiene que ver con la forma como está organizada la producción; y como se construyen las relaciones sociales entre empresarios, proveedores, distribuidores, productores, consumidores, empresas y bancos" (Cardona, 2003, p.59).

A su vez, los mercados de trabajo están regulados por un conjunto de instituciones -legislación laboral, mecanismos de control, sistemas de seguridad social y otrosque organizan su funcionamiento y cumplen una doble finalidad:

2 La concepción del trabajo como castigo puede rastrearse desde su misma etimología, esta palabra se deriva del latín tripalium que significa instrumento de tortura. 
"garantizar la eficiencia de este mercado y reforzar la posición de los actores estructuralmente menos fuertes en el mercado de trabajo y contribuir a condiciones de trabajo dignas" (Weller, 1998, p.24).

Al comienzo de la revolución industrial, las instituciones y los mecanismos de protección de los actores más débiles -los trabajadores- fueron escasos y casi nulos, de ahí que, el mercado de trabajo era la materialización de la competencia y explotación más brutal de los seres humanos. Esta situación se convertiría más adelante en una de las razones que incentiva el surgimiento de un modo alternativo de organización de la producción y el trabajo: el cooperativismo.

El cooperativismo emerge en Europa Occidental durante el periodo de la revolución industrial, como alternativa para superar las condiciones de pobreza y explotación de los trabajadores que fueron generadas por la transición del trabajo autónomo -artesanal- al sistema fabril bajo el modo de producción capitalista y el sistema de mercado autorregulado ${ }^{3}$.

Las desigualdades y problemas sociales de la época, inquietaron a algunos científicos sociales, entre ellos Robert Owen (1771-1858), Charles Fourier (1772-1837) considerados los padres de la cooperación en Inglaterra y Francia respectivamente, y a Philippie Buchez (1796-1865) y Louis Blanc (1811-1882), precursores de las cooperativas de trabajo asociado; cuyos planteamientos y aspiraciones por una sociedad más justa, participativa e incluyente y con mayor bienestar para los seres humanos, proporcionaría las bases para la construcción del movimiento cooperativo.

Con el transcurrir de los tiempos (siglo XX - décadas del 30 al 80), las condiciones históricas permitieron que los mercados de trabajo fuesen regulados por el Estado, el acuerdo tripartito entre éste, los empresarios y los trabajadores permite el surgimiento de los sistemas de seguridad y protección social y un sistema de trabajo típico -término utilizado por Raso (1999)-, caracterizado por la estabilidad del empleo, la contratación de tiempo completo y un régimen de garantías laborales.

Posteriormente, desde las últimas décadas del siglo XX un nuevo escenario competitivo influido por la mundialización, el desarrollo de las tecnologías de la información y comunicación y la incorporación del conocimiento como principal factor de producción, se comienza a vulnerar los sistemas de protección social, pues dio primacía a la preocupación por la eficiencia del mercado.

En este escenario competitivo la desregulación, la reducción de los costos de trabajo y la flexibilidad laboral se convierten en imperativo. El empleo convencional

3 Según Castells (1998), los modos de producción se caracterizan por la forma como se determinan la apropiación, distribución y uso de los excedentes. En el modo de producción capitalista existe una separación entre los productores y los medios de producción, el trabajo se concibe como una mercancía, la propiedad privada de los medios de producción es la base del control del capital y el propósito esencial es la maximización del beneficio para los dueños de aquel. 
(típico) de tiempo completo, subordinado legalmente y con todas las garantías laborales pierde su estatus y es considerado un obstáculo para la competitividad empresarial y el desarrollo del mercado. Por esta razón, en varios países de América Latina se emprenden reformas que buscan potenciar la flexibilidad laboral.

La flexibilidad laboral está conformada por dos dimensiones: $i$ ) la flexibilidad funcional que se refiere a la posibilidad de adaptación y capacitación de los trabajadores para la ejecución de múltiples actividades y procesos y, ii) la flexibilidad externa que se relaciona con la capacidad de ajustar la remuneración, el número y los tipos de contratación de los trabajadores. Esta última ha sido muy influyente en los procesos de reforma laboral en América Latina (Goldin, 2007) y ha originado un auge creciente en los procesos de subcontratación de personal (Bustamante, 2010).

Desde su sentido etimológico, subcontratación viene de dos vocablos latinos: $s u b$ que significa secundario, por debajo, y contractus que significa pacto, es decir, hace alusión a un pacto secundario que se establece entre un empleador -subcontratantey un tercero que se vincula con una organización, mediante la producción de bienes o la prestación de servicios, a través de la intermediación de alguien -subcontratista(Bustamante, 2006). Es una modalidad muy utilizada por las empresas para la tercerización de sus procesos y la conversión de sus relaciones laborales en acuerdos comerciales -con sociedades cooperativas, empresas de servicios temporales ${ }^{4} \mathrm{o}$ trabajadores independientes- ${ }^{5}$.

En el marco de la flexibilidad laboral, las cooperativas de trabajo asociado han sido vistas como una forma de subcontratación, que contribuye a disminuir el costo laboral y trasladar los riesgos del mercado al trabajador. Esto ha originado un crecimiento significativo en este tipo de organizaciones, promovido por empresas públicas y privadas que sistemáticamente han desvinculado sus trabajadores y los inducen a formar cooperativas para continuar prestando sus servicios -con unas condiciones diferentes- y con total desconocimiento de los principios y valores que constituyen la identidad cooperativa.

En síntesis, el desarrollo histórico del cooperativismo de trabajo asociado ha estado ligado a los avatares del mercado de trabajo. Su advenimiento es la respuesta a los efectos indeseables que trajo consigo la instauración del sistema industrial y

4 Las empresas de servicios temporales (EST) son organizaciones que suministran personal temporal a un tercero -llamado usuario-, para este propósito recurren a la contratación directa de personas naturales ante las cuales tiene el carácter de empleador -por lo tanto, asumen todas las obligaciones laborales establecidas por la legislación- y las envía en misión a las dependencias de las empresas usuarias para realizar las tareas y actividades contratadas por éstas. Es decir, estas empresas están dedicadas a la intermediación laboral, ese es su objeto social. Estas empresas son distintas de las cooperativas de trabajo asociado en su naturaleza, propósito y régimen legal. Sin embargo, muchas cooperativas, en franca contravía con la ley, han asumido el rol de intermediarias laborales, así distorsionan su identidad.

$5 \quad$ El texto de Urrea (1999) presenta una revisión bibliográfica del proceso de subcontratación y su relación con la globalización y la desregulación laboral. 
de mercado, de igual modo, la crisis que en la última década enfrenta el sector, es consecuencia de la utilización inadecuada de estas organizaciones como instrumentos de intermediación y flexibilidad laboral.

\section{Marco legal del cooperativismo de trabajo asociado en Colombia}

Según la declaración de identidad cooperativa, formulada por la Alianza Cooperativa Internacional -ACI- en 19956, las cooperativas se basan en los valores de la autoayuda, la autoresponsabilidad, la democracia, la igualdad, la equidad y la solidaridad. De igual modo, los principios que deben seguirse para poner en práctica dichos valores son: la adhesión voluntaria y abierta; la gestión democrática por parte de los socios; la participación económica de los asociados; la autonomía e independencia; la educación, formación e información; la cooperación entre cooperativas y el interés por la comunidad (ACI, 1995).

Las cooperativas de trabajo asociado (CTA) se caracterizan por ser organizaciones sin ánimo de lucro, regidas por los principios cooperativos, que vinculan el trabajo personal de sus asociados y sus aportes para satisfacer sus necesidades y aspiraciones económicas, sociales y culturales en común, mediante una empresa de propiedad conjunta y gestión democrática (ACI, 1995). Según se establece en la Declaración Mundial sobre Cooperativismo de Trabajo Asociado, el principal objetivo de estas organizaciones es la creación y mantenimiento de puestos de trabajo sustentables que generen riqueza para mejorar la calidad de vida de los socios trabajadores y sus familias, dignificar el trabajo humano y promover el desarrollo comunitario y local, deben actuar de manera autónoma ante el Estado y terceros en lo referente al trabajo, la gestión, la disposición y manejo de los medios de producción (CICOPA, 2005).

En Colombia, el cooperativismo surge formalmente en el año de 1931 con la promulgación de la ley 134 a través de la cual se da vida jurídica a las cooperativas (Fajardo, 2003). Posteriormente, en el año de 1963 se reglamentan las cooperativas de producción y trabajo, antecesoras de las cooperativas de trabajo asociado. No obstante, éstas últimas sólo surgen jurídicamente con la Ley 79 de 1988. Diez años más tarde, en el año de 1998 mediante la Ley 454, el gobierno nacional define el marco conceptual de la economía solidaria, sector que incluye las CTA, y reestructura las instituciones gubernamentales encargadas del registro y control de dicho sector. Finalmente, en el año 2008 mediante la Ley 1233 se precisa algunos elementos sobre los aportes a la seguridad social, se crean unas contribuciones especiales

6 La ACI es una organización no gubernamental fundada en Londres en el año de 1895; agrupa a la mayoría de organizaciones cooperativas en todo el mundo, forma una red económica internacional que promueve el cooperativismo. Participa en la Organización de las Naciones Unidas, en calidad de órgano consultivo 
-parafiscales- a cargo de las cooperativas de trabajo asociado y se fortalecen los mecanismos de control sobre estas entidades.

En la Figura 1 se representa la evolución del marco jurídico del cooperativismo de trabajo asociado en Colombia, en el que se pueden identificar tres etapas: la de antecedentes que corresponde aquel periodo normativo en el que no existía taxativamente esta figura cooperativa, pero que constituye el primer paso para su conformación; una segunda etapa de surgimiento a partir del año 1988 cuando nacen a la vida jurídica las CTA y, finalmente, una etapa de expansión en la que se registra un crecimiento acelerado en su constitución y vinculación de asociados ${ }^{7}$. Adicionalmente, la figura esquematiza el grado de especificidad y control que proporciona el marco jurídico de las CTA, tal como se observa en el esquema, puede decirse que éste es bajo debido a que aún no existe un régimen legal propio del trabajo asociado -en materia tributaria, de seguridad social- (Farné, 2008, p.280), así como los mecanismos de control sobre su creación y funcionamiento son insuficientes o por lo menos no arrojan aún resultados que demuestren lo contrario ${ }^{8}$.

Figura 1. Evolución del marco jurídico del cooperativismo de trabajo asociado en Colombia

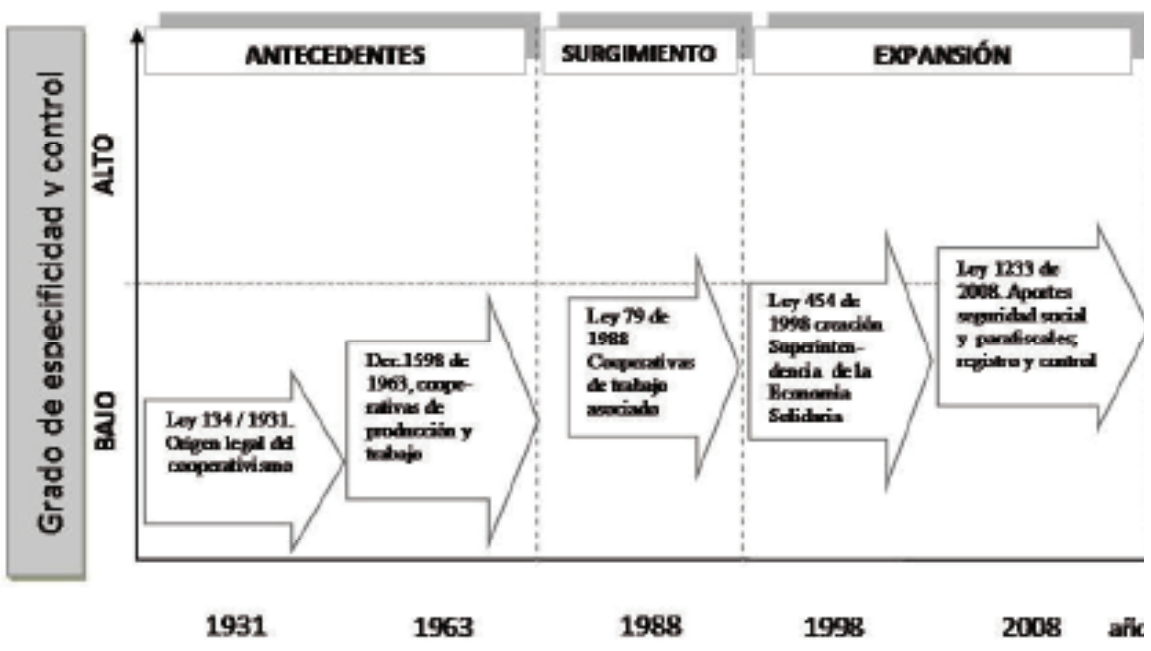

Fuente: elaboración propia

$7 \quad$ Un estudio detallado respecto a la situación del sector puede consultarse en: Confecoop $(2009,2010)$.

8 A pesar de las denuncias realizadas en contra de las arbitrariedades cometidas por algunas cooperativas de trabajo asociado, las acciones y sanciones impuestas en contra de éstas parecen insignificantes. 
Desde hace varios años, organismos internacionales como la Organización de las Naciones Unidas (ONU) y la Organización Internacional del Trabajo (OIT) han reconocido la importancia del cooperativismo como opción de desarrollo, generación de empleo, bienestar e inclusión a la vida laboral de la población menos favorecida, así está contemplado en la Declaración de Copenhague sobre Desarrollo Social (1995). De igual modo, estas organizaciones han considerado prioritario estimular y crear un entorno favorable para el desarrollo y promoción del cooperativismo, tal como lo establece la Resolución 56/114 de 2001 aprobada por la Asamblea General de la ONU, así como en la Recomendación 193 de 2002 de la OIT.

Los lineamientos internacionales anteriormente mencionados han permeado las políticas del gobierno colombiano sobre cooperativismo, tal como se ilustra en la Figura 2.

Figura 2. Lineamientos internacionales y nacionales del cooperativismo de trabajo asociado en Colombia

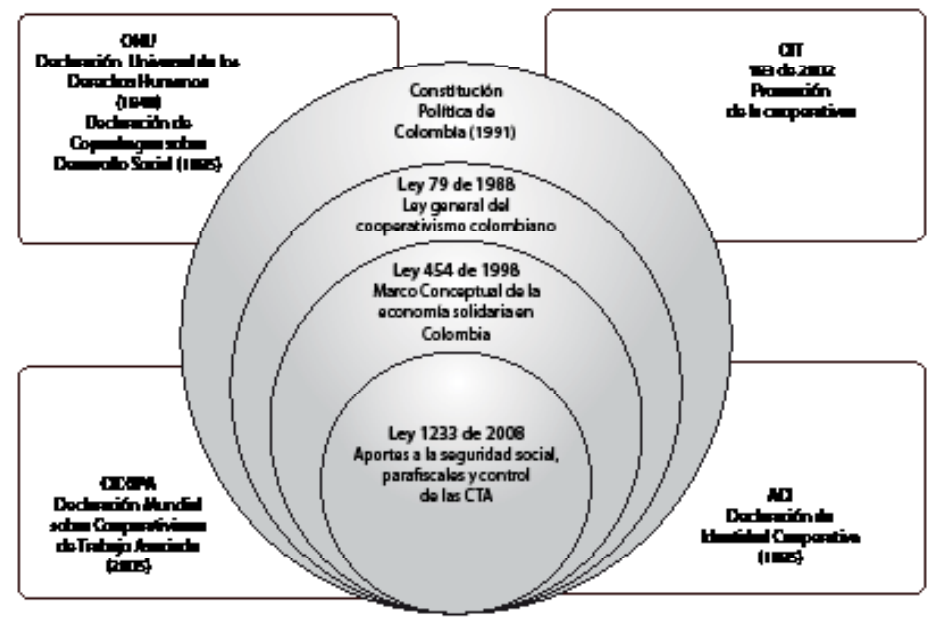

Fuente: elaboración propia

En sus dos décadas de existencia formal en Colombia, las CTA han presentado un crecimiento significativo, al año 2009 existían 4.111 CTA que representan el 50,60\% del total de las cooperativas, con una generación de empleo de aproximadamente 550.000 puestos de trabajo que equivalen el $2,98 \%$ de la población ocupada en el país (Confecoop, 2010). Sin embargo, aunque las cifras parecen optimistas, el panorama 
en cuanto a la calidad de los empleos generados y a la creación de valor económico y social por este tipo de organizaciones, es poco alentador, tal como lo expresa el mismo gremio cooperativo a través de Confecoop (2009), al igual que otros autores como Urrea (2007) y Farné (2008).

Ahora bien, si el modelo cooperativo está regido por unos principios que constituyen su identidad, y en los que la creación de empleo, inclusión y desarrollo económico y social son los supuestos de base: ¿Por qué en su puesta en práctica ha generado en algunos casos bienestar y en otros inequidad? ¿Cómo explicar esta contradicción? La respuesta a esta pregunta puede encontrarse en dos dimensiones: i) la coyuntura económica y política en la que surge y se expande este tipo de organizaciones, tal como lo expresa Zabala (2007) y ii) la laxitud en los controles gubernamentales sobre la creación y funcionamiento de estas cooperativas. En ambas dimensiones, las actitudes del gobierno, los empresarios y quienes dirigen las cooperativas, contribuyen a la proliferación de arbitrariedades en contra de la calidad del trabajo y los principios cooperativos.

Con respecto a la primera dimensión, el surgimiento de las CTA coincide con un periodo de modernización del Estado y las industrias colombianas, en el cual el adelgazamiento de las estructuras organizacionales de las entidades públicas y privadas y la flexibilización de la contratación laboral, se constituían en imperativos. Así, entonces, las CTA fueron vistas como la solución a los problemas estructurales y financieros de las organizaciones. A través de esta figura cooperativa era posible contratar los trabajadores con unas condiciones diferentes a las exigidas por la legislación laboral, es decir, se hace una intermediación laboral expresamente prohibida por ley para este tipo de organizaciones, casi siempre en detrimento de la calidad de la remuneración y la cobertura en seguridad social de los trabajadores asociados, en comparación con los trabajadores asalariados o dependientes, tal y como se evidencia en las investigaciones de Urrea (2007), Aricapa (2006a, 2006b, 2008); Bustamante (2006) y Botero y Mejía (2004).

Entonces, el cooperativismo de trabajo asociado deviene, en muchos casos, en una suerte de perversiones que distorsionan la esencia de esta forma de organización. En lugar de generar mayor equidad, participación y bienestar para los seres humanos, esta figura ha sido utilizada como un instrumento para reducir los costos laborales, generar precariedad laboral y en algunos casos exclusión de las coberturas mínimas en seguridad social que cualquier trabajador tendría derecho.

En cuanto a la segunda dimensión, es preciso mencionar la falta de rigurosidad y contundencia en la regulación y control gubernamental sobre las CTA (Farné, 2008, p.276), aunque existen controles y entidades encargadas de la supervisión -como el Ministerio de la Protección Social y la Superintendencia de Economía Solidaria-, la operacionalización de dichos controles y los recursos para hacerlos resultan insuficientes. Más aún, el mismo gobierno a través de las entidades públicas ha sido, en algunos casos, promotor de los abusos indebidos de la figura del cooperativismo 
de trabajo asociado, al inducir a algunos trabajadores -especialmente en el sector de la salud- a organizarse en CTA para prestar sus servicios; tal como puede constatarse en las Sentencias de Tutela de la Corte Constitucional No. 336 de 2000, 1080 de 2004 y en los testimonios que sobre este aspecto presenta Urrea (2007).

A pesar de lo anteriormente expuesto, no puede generalizarse los abusos cometidos, ni mucho menos desconocer que en otros casos, el cooperativismo ha generado oportunidades de bienestar y desarrollo para sus asociados y las comunidades en las cuales se encuentran inscritas. En Colombia, por ejemplo son reconocidos los casos de CoopVencedor -Pollos Vencedor- e Indupalma CTA ${ }^{9}$. Aunque se reconoce que es necesario profundizar en el estudio de los casos exitosos de cooperativismo de trabajo asociado y más concretamente en su gestión e incidencia en el desarrollo económico y social a nivel local y regional. En el siguiente capítulo se presentan algunas evidencias de CTA que han contribuido a generar bienestar para sus asociados y la comunidad.

\section{La generación de bienestar: el lado amable del cooperativismo de trabajo asociado}

Como se mencionó anteriormente, el movimiento cooperativo surge en el siglo XIX como expresión de los trabajadores que esperaban superar las dificultades y opresiones a las que habían sido sometidos en las empresas capitalistas, de tal manera que el trabajo dejara de concebirse como mercancía y el trabajador como recurso, y a través de una mejor organización de la producción y de las condiciones de vida de los trabajadores, éstos pudieran "alcanzar un desarrollo pleno" (García, 2005, p.389).

Es decir, el cooperativismo, además de constituirse en una opción para mejorar los aspectos económicos y laborales de los seres humanos, tiene como objetivo el generar espacios de bienestar y participación en procura de unas mejores condiciones de vida.

Entonces, el concepto de bienestar se entiende como

"el conjunto de sentimientos de satisfacción material e inmaterial que producen en las personas y colectividades una serie de condiciones materiales que no pueden reducirse únicamente al nivel de renta, sino que incluyen otras dimensiones importantes de la existencia humana como la salud, educación, servicios, infraestructuras, vivienda, seguridad, entorno, (...).” (Cano, Hernández y Chasco, 2003),

9 Una reseña sobre esta última se encuentra en Ganitsky (2005). 
o sea, el bienestar se asocia con aquellos factores que posibilitan a las personas una mejor calidad de vida, que le permiten vivir con tranquilidad y satisfacción. ${ }^{10}$

En este capítulo se describen algunas acciones realizadas por cooperativas de trabajo asociado del sector de la confección, ubicadas en el oriente antioqueño que, fieles a su naturaleza, principios y valores, han procurado generar bienestar para sus asociados y la comunidad. En el desarrollo de la investigación que sustenta este artículo, se ha utilizado un muestreo no probabilístico intencional, con criterios de representatividad cualitativa; en la elección de los casos objeto de estudio se definieron como criterios: la antigüedad de la empresa -mínimo 10 años de creación-, el número de trabajadores -superior a 200 asociados- y el sector en el que se desempeñan: confección. La razón de elegir este tipo de sector se fundamenta básicamente en la importancia de esta actividad en la economía colombiana, ya que es intensivo en mano de obra de media y baja calificación, por lo tanto, la prosperidad o adversidad de las empresas del sector tiene un impacto económico y social significativo en las regiones en las que se inscribe su actividad.

En el municipio de El Santuario ${ }^{11}$ desde el año de 1985 con el patrocinio de Leonisa S.A ${ }^{12}$ inició Ecooelsa CTA -Empresa Cooperativa de El Santuario-, una cooperativa de trabajo asociado dedicada a la confección ${ }^{13}$. En su asamblea de constitución participaron 30 asociadas y siete socios; la idea de sus promotores era generar fuentes de trabajo para la población más necesitada. Así lo confirma el testimonio de una de las asociadas vinculada hace más de 21 años con la cooperativa ${ }^{14}$ :

Esa cooperativa llegó acá a El Santuario, en primera instancia buscando la gente que más necesitaba del empleo, inclusive a uno le hacían entrevista en la casa, para ver cuántos hijos eran, qué hacían y luego le hacían unas pruebas. Al pasar esas pruebas lo enviaban a hacer un curso y luego lo llamaban a trabajar (EE3)

La capacitación de las personas estuvo a cargo del Sena y de la empresa patrocinadora durante los primeros años. Cada tres meses se programaban los cursos de capacitación para el manejo de las máquinas y de los oficios manuales requeridos. Posteriormente, a partir del año 1998, la cooperativa comenzó a realizar

10 Aunque se reconoce que el concepto de bienestar puede comprenderse desde dimensiones externas como las mencionadas -posibilidades de acceso a bienes y servicios relacionados con la alimentación, la vivienda, la educación, la salud, la seguridad y demás- así como a las dimensiones internas de la persona como, por ejemplo, el placer y la felicidad, entre otras, este trabajo se enfoca en las primeras (dimensiones externas). Para ampliar este concepto puede consultarse: Cano, Hernández y Chasco (2003), Valdés (1991)

11 El Santuario es un municipio del Oriente Antioqueño situado a 59km de Medellín (capital del Departamento de Antioquia), con una población de aproximadamente 26.300 habitantes (según el Censo del DANE de 2005). La agricultura, la ganadería, el comercio y la confección, constituyen sus actividades económicas principales.

12 Reconocida empresa colombiana que confecciona y comercializa ropa interior.

13 Inicialmente, Ecooelsa se constituyó como una empresa cooperativa de naturaleza limitada, posteriormente se transformó en una cooperativa de trabajo asociado.

14 Por asuntos éticos de la investigación se reservan los nombres de las personas entrevistadas. 
dichos programas con sus propios recursos humanos y financieros y con el aval del Sena, la capacitación estaba dirigida a los asociados de la cooperativa $\mathrm{y}$, en general, a los habitantes del municipio, algunos de éstos se beneficiaron de la cualificación y lograron constituir sus propias empresas de confección ${ }^{15}$.

En coherencia con los principios cooperativos, la educación y la formación han sido prioridades en los programas de Ecooelsa CTA. Con el apoyo de una institución educativa, la cooperativa posibilitó a un gran número de sus asociados terminar el bachillerato, suministrando las instalaciones y los recursos económicos necesarios, lo que ha permitido a muchos de ellos superarse y constituirse en ejemplo para sus familiares. A través de los fondos del comité de educación, algunos de ellos también han logrado realizar sus estudios profesionales lo que ha generado admiración en sus compañeros, según lo expresa un asociado entrevistado:

Yo admiro mucho el progreso físico y también de las personas, porque son muchas las personas que se han capacitado, han llegado a hacer la universidad utilizando préstamos del comité de educación (EE4)

Los programas de formación realizados por la cooperativa no sólo han contribuido a mejorar la cualificación técnica de las personas, sino que además, han contribuido a desarrollar sus capacidades artísticas y deportivas. Anualmente se programan los cursos que los asociados proponen, entre ellos programas de música, elaboración de pesebres, pintura, así como programas y torneos deportivos para los asociados, sus familias y, en general, la población de El Santuario.

En lo referente al aspecto deportivo cabe mencionar que la cooperativa cuenta con espacios para la práctica de baloncesto, microfútbol, voleibol, balonmano, artes marciales, aeróbicos y sus escenarios deportivos sirvieron para la realización de los Juegos Regionales en 1993 y para los XIX Juegos Deportivos Departamentales de Antioquia en 1996 (Torres, 2000).

La posibilidad de facilitarles a sus asociados la adquisición de vivienda propia ha sido otro de los programas con gran impacto social que ha liderado Ecooelsa. Del total de sus asociados más del $80 \%$ cuenta con casa propia, es decir, aproximadamente 325 personas, gracias a los préstamos realizados con recursos de la cooperativa, sobre este asunto obsérvese el testimonio de un asociado:

[La cooperativa] nos ha hecho préstamo para vivienda con muchas facilidades de pago y, como siempre las utilidades de la empresa nos las han repartido por partes iguales, todos hemos sido iguales allá y eso nos ha ayudado muchísimo. Yo creo que el que no tiene casa en la cooperativa es porque no quiere, porque a todos nos

15 Según información suministrada por la cooperativa hasta el año 2003 se habían capacitado más de 1.700 personas del municipio de El Santuario. 
han hecho préstamo para pagarlo muy fácilmente y esa es una de las principales cosas que yo tengo que agradecerle a la empresa fue conseguir casa propia. (EE3)

Según el testimonio del gerente, los asociados que aún no tienen casa propia es porque han ingresado recientemente a la cooperativa y no han alcanzado a consolidar un ahorro que les ayude a completar lo que la cooperativa presta para vivienda (hasta 32 millones de pesos) y así cubrir el costo de ésta, máxime cuando en los dos últimos años se ha incrementado considerablemente el precio de los inmuebles en el Municipio de El Santuario.

De igual manera, la formación integral y la preocupación constante porque el asociado pueda vivir plenamente en su trabajo, en su familia y en su municipalidad, son algunas de las experiencias positivas que este modelo del cooperativismo de trabajo asociado les ha traído a los habitantes de El Santuario:

Mi experiencia ha sido muy rica, llevo mucho tiempo y siempre me he sentido muy bien. Trabajando [en la cooperativa] la vida no se siente y son muchas las mejoras. Uno antes vivía muy limitado, en cambio ahora uno puede decir que puede aportar para la casa, se siente uno muy bien. Le doy gracias a Dios por el trabajo que me ha regalado, y si uno mira las alternativas de trabajo la mejor es ésta [cooperativismo], porque nos han aportado mucho integralmente, se preocupan tanto por lo económico y lo personal, porque ellos saben que cultivando los valores y los talentos, la persona puede ser más productiva y se preocupan mucho por el crecimiento personal, no es solamente que produzca y produzca sino que también se cultive uno como persona. (EE4)

Este testimonio, sirve para confirmar que las cooperativas son asociaciones de personas, lo que priman son los seres humanos, independientemente de su contribución material para la conformación del capital social, en este sentido, tal como lo expresa Giacalone y Thompson (2006) parten de una visión centrada en el ser humano (human-centered worldview).

La participación en la gestión, en los programas y en las decisiones que se toman en la cooperativa, es otra característica muy valorada por los asociados, sobre su experiencia en la cooperativa con respecto a la participación, un asociado manifestó

(...) ha sido muy buena porque me han dejado participar en todo, o sea yo puedo participar en todo lo que se haga, en lo político, en los comités, nos permiten estar en muchas actividades y continuamente nos capacitan. (EE1)

De acuerdo con los testimonios expresados por los asociados entrevistados, todos tienen claro que ellos son dueños de la cooperativa y que la gestión es democrática, conocen los órganos de administración y los mecanismos para participar en éstos, es decir, los asociados tienen plena conciencia de lo que es un modelo cooperativo y de la posibilidad que tienen de participación y de gestión democrática. 
En síntesis, puede afirmarse que en sus más de dos décadas de existencia Ecooelsa CTA ha logrado constituirse en la industrial de confección más grande del municipio $^{16}$, ha generado en la actualidad aproximadamente 400 puestos de trabajo permanentes, lo que redunda en beneficio de sus asociados y de la población en general, razón por la cual una de las personas entrevistadas expresó: “esta cooperativa es lo mejor que le ha pasado a El Santuario" (EE1). Así entonces, el bienestar de sus asociados -como fuente de empleo, posibilidad de acceso a educación, vivienda, seguridad social, recreación- y el aporte al desarrollo económico y social de la región han sido el fruto de Ecooelsa tras varios años de cooperación.

De otro lado, en el municipio de Marinilla $^{17}$ se encuentran también dos cooperativas de trabajo asociado del sector de la confección, éstas son: Incoomar con más de 25 años de funcionamiento y aproximadamente 320 asociados permanentes y Coopimar constituida en el año 2001, ésta tiene actualmente 400 asociados y con expectativas de llegar a 1.000 asociados en el mediano plazo.

Estas cooperativas han contado con el patrocinio de Leonisa S.A., de igual manera la cooperativa más joven también ha recibido el apoyo de: Ecooelsa, Incoomar, Municipio de Marinilla y de diversas entidades internacionales y nacionales como: la Unión Europea, la Agencia de los Estados Unidos para el Desarrollo Internacional -USAID ${ }^{18}$-, la Agencia presidencial para la acción social y la cooperación internacional -ACCIÓN SOCIAL- y la Corporación Programa de Desarrollo para la Paz -PRODEPAZ-, entre otros.

Los esquemas de gestión, de producción y los programas de educación, formación y vivienda, en estas cooperativas son similares a los descritos en la cooperativa de El Santuario. En Incoomar, todos los asociados tienen casa propia, éstos se unieron y construyeron un barrio que lleva el nombre de la cooperativa y de acuerdo con lo expresado por Duque "son las viviendas mejor desarrolladas urbanística y arquitectónicamente en el municipio" (2001, p.17) ${ }^{19}$.

Los programas de formación en música ofrecidos a los asociados de las cooperativas de Marinilla, los cuales se han hecho extensivos a sus familias, han posibilitado la conformación desde el año de 1994 de la Banda infantil y Juvenil de

16 Esta información fue verificada con las estadísticas que publica la Superintendencia de Economía Solidaria, entidad que vigila a las cooperativas en Colombia.

17 Marinilla es un municipio del oriente antioqueño, con una población de 41.200 habitantes aproximadamente. Sus actividades económicas principales son la agricultura, la floricultura y la confección.

18 USAID es la Agencia de Estados Unidos para el Desarrollo Internacional, es la principal agencia gubernamental responsable de la administración y financiación de los programas de asistencia social, económica y humanitaria del gobierno de Estados Unidos a nivel mundial. En Colombia la USAID, en coordinación con la Agencia Presidencial para la Acción Social y la Cooperación Internacional, ACCIÓN SOCIAL, lleva a cabo un esfuerzo que se llama MIDAS "Más Inversión para el Desarrollo Alternativo Sostenible" Información obtenida en la página de Internet: http://www.midas.org.co, consultada el 8 de diciembre de 2008.

19 Un recorrido por el municipio permitió verificar la afirmación que hace el autor citado. 
Música Incoomar, que actualmente cuenta con 45 integrantes, niños y jóvenes entre los 7 y 19 años de edad. Esta banda ha representado al Municipio de Marinilla en diferentes eventos musicales a nivel local, departamental y nacional ${ }^{20}$.

Según lo expresado anteriormente, Coopimar CTA ha contado con el apoyo de diversas entidades nacionales e internacionales que se han vinculado a esta iniciativa de asociatividad por cuanto la cooperativa ha generado oportunidades de empleo y de mejoramiento de la calidad de vida para madres cabeza de familia y población desplazada por la violencia, esto ha hecho que esta organización sea beneficiaria de diferentes programas de cooperación.

A través del programa Midas -más inversión para el desarrollo sosteniblefinanciado por USAID, ha recibido asistencia técnica y financiera para la capacitación de los asociados; del proyecto Esperanza Solidaria, el cual brinda oportunidades de empleo para la población desplazada y vulnerable del oriente antioqueño; del programa Coser liderado por PRODEPAZ, el cual busca fomentar la economía solidaria y ayudar a varias cooperativas de confección a desarrollar una marca propia así como liderar la creación de una comercializadora de los productos.

En síntesis, puede afirmarse que las cooperativas de trabajo asociado anteriormente descritas han contribuido a generar bienestar y a mejorar las condiciones de vida -acceso a servicios educativos, seguridad social, vivienda, recreación- y laborales de sus asociados y, en general, de la municipalidad, lo que constituye un ejemplo de las potencialidades del modelo cooperativo para generar oportunidades de trabajo, de desarrollo económico y social y de inclusión a la población vulnerable.

\section{La inequidad laboral: un lado oscuro del cooperativismo de trabajo asociado ${ }^{21}$}

La declaración sobre identidad cooperativa promulgada por la ACI -como se mencionó anteriormente- contempla entre otros valores la equidad. Aristóteles consideraba la equidad como un perfeccionamiento de la justicia, para éste "lo que es equitativo, aún siendo justo, no lo es de conformidad con la ley; es como un mejoramiento de lo que es justo, según la ley" (1967, 1137b1). Según lo afirma Altarejos, "la justicia consiste en dar a cada uno lo que es debido", se manifiesta generalmente en el ámbito social y se rige por leyes de carácter general (2003, p.173). Entonces, la equidad apela a la justicia, tiene en cuenta la singularidad y opera en aquellos casos en los cuales la aplicación de la ley puede producir efectos injustos.

20 Información obtenida de la página Web: http://incoobandasinfonica.blogspot.com/ y verificada posteriormente a través de una visita a las instalaciones de la empresa.

21 Los argumentos que se presentan en este numeral se sustentan en fuentes secundarias -artículos y tesis de maestría- encontradas en el contexto colombiano, por lo tanto, el alcance de las afirmaciones se limita a dicho contexto. 
Como corolario, podría decirse que la inequidad es aquello que no es justo o que aún obrando conforme a la ley produce injusticia.

En Colombia existen regímenes diferenciados para el trabajo dependiente y el trabajo asociado, en términos de derechos, obligaciones y responsabilidades. No obstante, en algunas organizaciones concurren en el mismo escenario de trabajo y en ejecución de iguales tareas, tanto empleados asalariados como asociados, que bajo el amparo de la ley son sometidos a situaciones de inequidad -diferencias en la remuneración y en el acceso a algunos beneficios como el servicio de restaurante y de transporte-. Por esta y otras razones que se explicarán más adelante el modelo del cooperativismo de trabajo asociado ha sido objeto de críticas $^{22}$.

La década de los ochenta (1980) en la que nacen jurídicamente las CTA en Colombia, coincide con un periodo de modernización del Estado y las industrias, en el marco del proceso de apertura económica ${ }^{23}$. En medio de estos acontecimientos de gran trascendencia en la historia reciente del país, las cooperativas de trabajo asociado fueron vistas como la panacea para los problemas, en palabras del doctor Enrique Valderrama, Superintendente de Economía Solidaria "parece que para todas las enfermedades que ocurrían en Colombia, la solución era una cooperativa de trabajo asociado" 24 . Bajo este argumento, el Estado Colombiano y algunas empresas fueron los primeros en patrocinar el surgimiento de estas organizaciones cooperativas.

Es decir, a expensas del cooperativismo lo que se pretendió fue flexibilizar el trabajo y disminuir los costos laborales de las entidades públicas y privadas bajo una figura que se encontraba al margen de la legislación laboral. De este modo, algunos trabajadores asalariados fueron despedidos y las empresas comenzaron a contratar su personal a través de cooperativas de trabajo asociado.

Lo grave del asunto es que este patrocinio a las CTA se hizo, en muchos casos, con total desconocimiento de lo que significa este modelo cooperativo y violentando el derecho fundamental de la libre asociación protegido por la Constitución Nacional. La conformación de algunas CTA obedeció a la insinuación del empleador, que supeditó

22 Al respecto, son ilustrativas las palabras del político colombiano Alejandro Guerra Serna cuando se refiere a las CTA como cooperativas de trabajo disociado, en el artículo de su autoría publicado el 8 de octubre de 2004 en el periódico El Colombiano.

23 Según lo expresa Goldin (2007, p.9), el proceso de apertura económica en varios países de América Latina coincide con una oleada reformista de las legislaciones laborales, al considerarlas como factores de restricción para la inversión y la competitividad de las empresas; el propósito de tales reformas fue reducir y flexibilizar los costos laborales, de modo que fueran ajustables a la demanda de los productos, recuperar el control de la fuerza de trabajo e introducir nuevos modos de organizar el trabajo y la producción. Precisamente, en esta coyuntura, toma auge el modelo del cooperativismo de trabajo asociado, como forma flexible de organizar el trabajo, disminuir el costo laboral y trasladar los riesgos del mercado al trabajador.

24 Información tomada de la intervención del Superintendente de Economía Solidaria en la reunión de la Comisión 013 de 2008 del Concejo de Medellín cuyo propósito era el estudio de la situación de las cooperativas y pre-cooperativas de trabajo asociado en las dependencias del Municipio de Medellín del nivel central y descentralizado, tal como consta en el Acta No.3 de 2008 de dicha comisión. 
la contratación de los trabajadores a la creación de la cooperativa. Así entonces, se distorsionó la esencia de esta figura de la economía solidaria que contempla dentro de sus principios el de la libre adhesión y se violenta el derecho de asociación ${ }^{25}$, teniendo en cuenta que en Colombia, tal como lo afirma la Corte Constitucional:

"la afiliación tanto como la pertenencia a una asociación son actos voluntarios y libres y dependen exclusivamente y por siempre de la libertad de la persona" (Sentencia T-454 de 1992).

A los problemas anteriores, se suma el del clientelismo, tal como lo denuncia Urrea (2007) algunas CTA que prestaban servicios a entidades públicas fueron convertidas en "bolsas de empleo político". Al respecto, este mismo autor señala que:

(...) los concejales eran quienes dirigían esas cooperativas, a quienes se les daban los contratos para que ellos las crearan con las personas que conformaban su grupo político; eran quienes determinaban quién sería el representante de la cooperativa (...) De modo que el representante de la cooperativa era una cuota política del concejal (...) (Urrea, 2007, p.164)

Entonces, se presenta una clara violación a los principios cooperativos de la adhesión libre y voluntaria, la gestión democrática por parte de los asociados y la autonomía e independencia, porque ahora resulta que algunos políticos son "dueños" de las cooperativas y las gestionan según su conveniencia, tal como lo evidencia el testimonio citado $^{26}$.

Las CTA también han sido usadas "ilegalmente" para la intermediación laboral, máxime cuando el ordenamiento jurídico les prohíbe este tipo de actividad, la cual sólo está permitida para las empresas de servicios temporales, que tienen como finalidad enviar trabajadores en misión, para efectuar bajo la dirección del contratante una labor por un tiempo determinado, pero bajo el amparo de la legislación laboral. Haciendo caso omiso a la prohibición legal, algunos empresarios contratan a través de CTA el personal que requieren sus empresas, en algunos casos se desvinculan los trabajadores asalariados para posteriormente vincularlos como asociados, a través de una relación comercial con una CTA, desmejorando su remuneración y estabilidad laboral, tal como se presenta en la investigación de Bustamante (2006).

En nombre del cooperativismo de trabajo asociado algunos empresarios del sector público y privado han cometido gran cantidad de arbitrariedades y abusos en contra de la clase trabajadora y de la sociedad, en general. Por un lado, los trabajadores asociados resultaron afectados por la precariedad laboral, al no tener garantizado

25 Al respecto puede consultarse: las Sentencias de Tutela de la Corte Constitucional T-336 de 2000, T-1080 de 2004, T-291 de 2005 y las investigaciones de Aricapa (2006a, 2008), Urrea (2007).

26 Otros testimonios similares pueden encontrarse en las actas No.4 y 6 de la Comisión Accidental 097 de 2008 del Concejo de Medellín. 
por mandato expreso de la ley una compensación mínima y no estar cobijados integralmente por los beneficios del sistema de seguridad social, ni de las cajas de compensación durante el tiempo que la normatividad cooperativa lo permitió ${ }^{27}$. De otro lado, el Estado Colombiano dejó de recibir ingresos por concepto de aportes parafiscales de las CTA, lo que lógicamente disminuyó los rubros en inversión social en educación y protección infantil y familiar a través de los programas adelantados por el SENA -Servicio Nacional de Aprendizaje- y el ICBF -Instituto Colombiano de Bienestar Familiar- de los cuales se beneficia la sociedad colombiana.

El aumento en la productividad, es considerado otro beneficio de la tercerización de los procesos organizacionales, a través de cooperativas de trabajo asociado ${ }^{28}$, teniendo en cuenta que en algunos casos la remuneración por los servicios prestados por la cooperativa y sus asociados se pacta "al destajo" o por unidad, lo que constituye un incentivo para mejorar la productividad, tal como lo expresan Gallego y Ruiz:

(...) el trabajador al cambiar de modalidad de contrato [laboral a prestación de servicios] se esfuerza cada vez más por estar acorde con los estándares de desempeño establecidos con la empresa contratante, máxime si uno de los requisitos a cumplir en el contrato es el rendimiento productivo, sumado a su pago por productividad. Esto está llevando a que los trabajadores se esfuercen más por cumplir a cabalidad con cada una de las funciones pactadas, al estar mucho más regulada su estabilidad por la productividad que por el tipo de contrato (2004, p.120).

Esta situación resulta paradójica. Por un lado, la empresa se beneficia del aumento en la productividad, pero al mismo tiempo puede generarse un ambiente hostil entre los trabajadores vinculados y los asociados, lo que afecta su motivación y, por consiguiente, el clima laboral. Por otro lado, los trabajadores asociados se benefician de los aumentos en la productividad por los incentivos que esto les genera pero, a su vez, son cada vez más explotados pues se les exige un rendimiento máximo por un pago mínimo, de esta forma se hace evidente lo que Aktouf denomina la doble contradicción "un salario mínimo por un trabajo máximo" (2001, p.556). El siguiente testimonio es bastante claro para ilustrar tal contradicción:

La eficiencia del personal cooperativo es mayor que la del personal temporal o vinculado, porque el cooperativo se gana día a día su puesto y a los temporales o vinculados al llevar mucho tiempo en el oficio van cogiendo una conducta un

27 No obstante, con la expedición de la Ley 1233 de 2008 se ha tratado de corregir estas falencias. En el artículo de Farné (2008) pueden consultarse los avatares de la política gubernamental sobre cooperativas de trabajo asociado, que tal como lo señala dicho autor, ha transcurrido en medio de ambigüedades e incoherencias.

28 Orellana afirma que en las empresas de trabajo asociado (entre ellas las CTA), se propician los comportamientos individuales favorables (por ejemplo, el aumento en la productividad) de los trabajadores porque esto repercute directamente en los resultados de la empresa de la que ellos son propietarios (2002, p.51) 
tanto pasiva (...). Y entonces (...) en los planes de incentivos que se tienen con la cooperativa, la gente se estimula a producir más (...) más por el mínimo. (Botero y Mejía, 2004, p.92)

El trabajador asociado se encuentra más presionado a aumentar su productividad y eficiencia porque sabe que su remuneración y estabilidad laboral depende de ello. Del mismo modo, aunque produce más que los trabajadores vinculados su compensación es inferior, lo que se constituye en inequidad laboral. Este tipo de situaciones se presenta en aquellas organizaciones que recurren a cooperativas de trabajo asociado para proveerse del personal que requieren en sus procesos productivos, pero que a su vez éstos son realizados por trabajadores directamente vinculados a la empresa. Es decir, tanto los asociados como los empleados directos comparten el mismo escenario de trabajo -instalaciones, equipos, herramientas-, inclusive muchos de ellos realizan las mismas tareas, sin embargo, sus condiciones de contratación -laboral o comercial-, la remuneración y demás compensaciones suelen presentar diferencias significativas, obsérvese, por ejemplo, algunos testimonios contenidos en la investigación de Botero y Mejía:

(...) la respuesta a la pregunta relacionada con la compensación del asociado en comparación con el salario del vinculado es prácticamente unánime, tanto los gerentes de relaciones industriales como los asociados, son conscientes de que el dinero que recibe el asociado es menor comparado con el del vinculado: “(...) te puedo decir que entre un $20 \%$ y un $40 \%$ por debajo, de un asociado respecto a un empleado, sin contar prestaciones sociales, porque si se tiene en cuenta las prestaciones sociales, este factor sería más alto. (2004, p.91)

Este tipo de diferencias en la remuneración son un ejemplo claro de las inequidades laborales a las que son sometidos algunos trabajadores asociados, máxime cuando ellos son conscientes de la situación lo que puede originarles desmotivación, falta de compromiso en su trabajo, inclusive algunos resentimientos, tal como se puede apreciar en el comentario expresado por un asociado, cuando se le pregunta si existen diferencias entre su remuneración y la de los trabajadores vinculados ${ }^{29}$ :

Es mucha la diferencia, empezando por el aguinaldo (...) el aguinaldo de la cooperativa son $\$ 20.000$, mientras uno de la empresa está recibiendo $\$ 600.000$ ó $\$ 700.000$, uno es el que menos está recibiendo (...). Sí, yo estoy realizando la misma labor que desempeña un empleado directo (...) por eso digo yo que no es justo (...). (Botero y Mejía, 2004, p.91)

Para hacer menos visibles tales inequidades laborales, algunas empresas optan por mantener separados a sus empleados directos y a los trabajadores asociados, de

29 Testimonios similares sobre la inequidad laboral pueden consultarse en Iranzo y Ritcher (2008, p.11-13) 
esta manera se reducen los riegos de afectar la moral de éstos últimos, su motivación $y$, por consiguiente, el clima laboral ${ }^{30}$. Sin embargo, las situaciones de inequidad persistirán mientras que las cooperativas de trabajo asociado sean utilizadas como simples intermediarias que permiten, además de flexibilizar la mano de obra, disminuir el costo laboral y mientras los asociados no sean verdaderos propietarios de sus medios de producción y del producto de su trabajo, tal como lo establece la identidad cooperativa y el ordenamiento jurídico colombiano sobre este tipo de organizaciones.

\section{Consideraciones finales}

Desde sus orígenes el cooperativismo de trabajo asociado está cimentado sobre principios que propenden por el desarrollo de la solidaridad, la equidad, el trabajo autogestionario y la propiedad compartida de los asociados. No obstante, en su puesta en práctica, ha dado lugar a dos realidades bien distintas; por un lado, la generación de bienestar para los asociados, su grupo familiar y la comunidad en general; de otro lado, han sido denunciadas por precarizar el trabajo y generar situaciones de inequidad laboral.

Algunos académicos y políticos del país han dedicado parte de sus esfuerzos a denunciar las irregularidades y atropellos cometidos contra los trabajadores en algunas organizaciones que se atribuyen el nombre de cooperativas de trabajo asociado, lo cual ha contribuido a desacreditar este gremio y, por consiguiente, se desconocen las labores de bienestar económico y social que ejercen algunas de ellas.

Por esta razón, se requiere un mayor control del gobierno sobre este tipo de organizaciones para evitar que se distorsione la identidad cooperativa en búsqueda de fines adversos a sus principios. A su vez, son necesarios mayores esfuerzos investigativos para comprender cuáles han sido las dinámicas de constitución y de gestión de aquellas que han tenido un impacto significativo en el bienestar de sus asociados y de las regiones en las cuales se encuentran inscritas, de tal manera que se puedan constituir en referentes para la promoción de nuevos proyectos cooperativos para el desarrollo económico y social.

30 Autores como Iranzo y Richter (2008), Brooks (2006), Bustamante (2006), Gallego y Ruiz (2004) han investigado los efectos de la subcontratación de personal -la cual es ejercida entre otras modalidades a través de CTA- en la productividad, los conflictos, la motivación y el compromiso laboral. 


\section{Referencias Bibliográficas}

Aktouf, O. (2001). La Administración: entre tradición y renovación. Segunda edición. Cali: Univalle-Gaetan Morin.

ACI - Alianza Cooperativa Internacional (1995). Declaración de la Alianza Cooperativa Internacional sobre la Identidad Cooperativa. Manchester - Reino Unido.

Altarejos, M. (2003) La equidad: fundamento ético para una educación intercultural. Estudios sobre educación, No.5, pp. 173-180

Aricapa, R. (2006a). Las CTA del sector azucarero: ¿Flexibilización o salvajismo laboral? Revista Cultura y Trabajo, No. 69, pp.1-5

Aricapa, R. (2006b). Las cooperativas de trabajo asociado en el puerto de Buenaventura: Caos y degradación laboral. Revista Cultura y Trabajo, No. 70, pp.1-6

Aricapa, R. (2008). Las CTA en el sector salud: La cadena del dolor. Revista Cultura y Trabajo, No. 74, pp.1-6

Aristóteles (1967). Ética a Nicómaco. En Aristóteles/Obras (Trad.: Francisco de P. Samaranch). Madrid: Gredos.

Botero, H. y Mejía, J. O. (2004). Gestión del recurso humano contratado a través de cooperativas de trabajo asociado en las empresas del sector textil y de la confección. Memoria de la investigación para optar al título de Magíster en Administración. Universidad EAFIT, Medellín.

Brooks, N. (2006). Understanding it Outsourcing and its potential effects on it workers and their environment. Journal of computer Information systems, Vol.46, No.4, pp. $46-53$

Bustamante, A. (2006). Algunas implicaciones de la subcontratación en la motivación de los trabajadores contratados bajo esta modalidad. Memoria de la investigación para el título de Magíster en Ciencias de la Administración. Universidad EAFIT, Medellín.

Bustamante, A. (2010). Cooperativismo de trabajo asociado: una opción estratégica (...) ¿De quién y para qué? Artículo presentado para publicación.

Cano, T., Hernández, I. y Chasco, C. (2003). Medición del bienestar social provincial a través de indicadores objetivos. Anales de economía aplicada. Recuperado el 13 de marzo de 2009 del sitio Web: http://www.asepelt.org/ficheros/ file/ anales/2003\%20-\%20almeria/asepeltpdf /111.pdf

Cardona, M. (2003). Algunas reflexiones sobre los mercados de trabajo y la industria maquiladora. Revista Universidad EAFIT, No. 102, pp.57-65 
Castells, M. (1998). La era de la información: economía, sociedad y cultura. Volumen 1 - La sociedad red. Madrid: Alianza editorial

CICOPA - Comité Ejecutivo de la Organización Internacional de Cooperativas de Producción Industrial, Artesanal y de Servicios (2005). Declaración Mundial sobre Cooperativismo de Trabajo Asociado. Oslo.

Colombia. Congreso de Colombia. Ley 134 (7, diciembre, 1931). Sobre sociedades cooperativas. Diario oficial: Bogotá, 1931, No. 21.866

Colombia. Congreso de Colombia. Ley 79 (23, diciembre, 1988). Por la cual se actualiza la legislación cooperativa. Bogotá: 1988

Colombia. Congreso de Colombia. Ley 454 (4, agosto, 1998). Por la cual se determina el marco conceptual que regula la economía solidaria y se dictan otras disposiciones. Diario oficial: Bogotá, D.C. 1998, No. 43.357

Colombia. Congreso de Colombia. Ley 1233 (22, julio, 2008). Por medio de la cual se precisan los elementos estructurales de las contribuciones a la seguridad social, se crean las contribuciones especiales a cargo de las Cooperativas y Precooperativas de Trabajo Asociado y se dictan otras disposiciones. Diario oficial: Bogotá, D.C. 2008, No. 47.058

Colombia. Corte Constitucional - Sala Séptima de Revisión. Sentencia T-454 de 1992. Magistrado Ponente: Dr. Jaime Sanín Greiffenstein. Santafé de Bogotá: 13 de julio de 1992

Colombia. Corte Constitucional -Sala Segunda de Revisión. Sentencia T-336 de 2000. Magistrado Ponente: Dr. Alfredo Beltrán Sierra. Santafé de Bogotá: 23 de marzo de 2000

Colombia. Corte Constitucional -Sala Primera de Revisión. Sentencia T-1080 de 2004. Magistrado Ponente: Dr. Jaime Araujo Rentería. Santafé de Bogotá: 29 de octubre de 2004

Colombia. Corte Constitucional -Sala Tercera de Revisión. Sentencia T-291 de 2005. Magistrado Ponente: Dr. Manuel José Cepeda Espinosa. Bogotá, D.C.: 31 de marzo de 2005

Colombia. Presidencia de la República. Decreto Ley 1598 de 1963. Por el cual se reglamenta un nuevo estatuto legal cooperativo. Bogotá: 1963

CONFECOOP - Confederación de Cooperativas de Colombia. (2009). Las cooperativas de Trabajo Asociado en Colombia. Observatorio Cooperativo, No.11, agosto de 2009, pp.1-28

CONFECOOP - Confederación de Cooperativas de Colombia. (2010). Situación de las CTA en Colombia ¿Qué muestran las cifras bajo el nuevo marco normativo? Observatorio Cooperativo, No.17, pp.1-71. 
De Coster, M. (1999). Sociologie du travail et gestion des ressources humaines. Bruxelles: De Boeck Université.

Duque, J. L. (2001). El empleo como motor del desarrollo local: la organización y el conocimiento para una producción municipal. El caso del municipio de Marinilla. Documento presentado en el Encuentro Municipio productivo y generación de empleo. Autonomía local y desarrollo sostenible: cooperar beneficiándose y beneficiarse cooperando.

Fajardo, M. (2003). Presencia del Cooperativismo en Colombia. Unircoop, Vol.1, No.2, pp. 121-138

Farné, S. (2008). Las cooperativas de trabajo asociado en Colombia: balance de la política gubernamental, 2002-2007. Revista de Economía Institucional, Vol.10 No.18, pp.261-285

Gallego, C. y Ruiz, M. (2004). El outsourcing de mano de obra y su incidencia en la competitividad organizacional de las grandes empresas de producción de la ciudad de Manizales. Trabajo de grado, Maestría en Gerencia del Talento Humano, Universidad de Manizales.

Ganitsky, J. (2005). Lecciones colombianas para afrontar con éxito los desafíos empresariales: Indupalma y las cooperativas de trabajo asociado (CTA). Revista Empresa, No.11, pp. 96-110

García, M. (2005). La discriminación del trabajo cooperativizado. CIRIEC - España, Revista de Economía Pública, Social y Cooperativa, No. 52, pp.387-409

Giacalone, R. A. y Thompson, K. R. (2006). Business Ethics and Social Responsibility Education: Shifting the worldview. Academy of Management Learning and education, Vol. 16, No.4, pp. 266-277

Goldin, A. (2007). Los derechos sociales en el marco de las reformas laborales en América Latina. Ginebra: Organización Internacional del Trabajo. Instituto Internacional de Estudios Laborales.

Iranzo, C. y Richter, J. (2008). Subcontratación y conflicto. El caso de la Siderurgia del Orinoco. Revista Gaceta Laboral, Vol.14 No. 1, pp. 5-34

Medellín. Concejo Municipal (2008). Actas de la Comisión Accidental 013 de 2008. Recuperado el 10 de enero de 2009, del sitio Web: http://www.concejodemedellin. gov.co

Orellana, W. (2002). El control en las empresas de trabajo asociado. Revisión crítica, desde una perspectiva de agencia, de los principales mecanismos de control y análisis de sus repercusiones organizativas. CIRIEC - España, Revista de Economía Pública, Social y Cooperativa, No. 42, pp.49-80. 
ONU - Organización de las Naciones Unidas (1995). Declaración de Copenhague sobre Desarrollo Social. Recuperado el 9 de abril de 2009, del sitio Web: http:// www.un.org/ documents/ga/conf166/aconf166-9sp.htm

ONU - Organización de las Naciones Unidas (2001). Resolución 56/114 de 2001 (A/ RES/56/114). Recuperado el 9 de abril de 2009, del sitio Web http://www. un.org/ Depts /dhl/spanish/resdecls/res56_2s.htm

OIT - Organización Internacional del Trabajo (2002). Recomendación 193 sobre la promoción de las cooperativas. Recuperado el 9 de abril de 2009 del sitio Web: http://www.ilo.org/ilolex/english/recdisp2.htm

Polanyi, K. (1992). La gran transformación. Los orígenes políticos y económicos de nuestro tiempo. México: Fondo de Cultura Económica.

Raso, J. (1999). Impacto de la mundialización de la economía en las relaciones laborales. Actualidad laboral y seguridad social, No.95, pp.4-21

Torres, E. (2000). Monografía deportiva de El Santuario. La historia del deporte santuariano en el siglo XX. Rionegro (Antioquia).

Valdés, M. (1991) Dos aspectos en el concepto de bienestar. Recuperado de Internet el 23 de enero de 2009 del sitio Web: http:/www.cervantesvirtual.com/ servlet/ SirveObras/024727764362 47507976613/cuaderno9/doxa9_04.pdf, pp. 69-89

Urrea, F. (1999). Globalización, subcontratación y desregulación laboral. En L. G. Arango y C. M. López, Globalización, apertura económica y relaciones industriales en América Latina (pp.50-91). Bogotá: Centro de Estudios Sociales CES, Universidad Nacional de Colombia.

Urrea, F. (2007). La rápida expansión de las cooperativas de trabajo asociado en Colombia. Controversia, No. 0188, pp.117-169

Weller, J. (1998). Los retos de la institucionalidad laboral en el marco de la transformación de la modalidad de desarrollo en América Latina. Santiago de Chile: CEPAL - Serie de reformas económicas.

Zabala, H. (2007, septiembre 30). Las Cooperativas de Trabajo Asociado. [Programa televisivo La fuerza de los argumentos, producido por Universidad de Antioquia]. Medellín: Canal Regional Teleantioquia. 